\title{
PERSEPSI MASYARAKAT MENGENAI SERVICE EXCELLENCE PRIA DAN WANITA TERHADAP LOYALITAS NASABAH
}

\section{THE PERCEPTION OF PUBLIC REGARDING SERVICE EXCELLENCE ON MEN AND WOMEN TO CUSTOMER LOYALTY}

\author{
Arfiani Sarah'1a; Metti Paramita²; Andri Brawijaya³ \\ 1aProgram Studi Ekonomi Syariah Fakultas Ekonomi Islam Universitas Djuanda Bogor, Jl. \\ Tol Ciawi No. 1, Kotak Pos 35 Bogor 16720, e-mail: sarah_arfiani@yahoo.co.id \\ 2Program Studi Ekonomi Syariah Fakultas Ekonomi Islam Universitas Djuanda Bogor, Jl. \\ Tol Ciawi No. 1, Kotak Pos 35 Bogor 16720 \\ 3Program Studi Perbankan Syariah Fakultas Ekonomi Islam Universitas Djuanda Bogor, Jl. \\ Tol Ciawi No. 1, Kotak Pos 35 Bogor 16720
}

\begin{abstract}
This study aims to find out how cimande community perception about service excellence in men and women to customer loyalty (study at BTPN Syariah KCP Ciawi). In this study using descriptive quantitative and using analysis Likert Scale and Chi Square method. Primary data was taken using questionnaire method with sampling using Slovin method as much as Fifty (50) samples from BTPN Syariah KCP Ciawi customer.This study aims to find out how cimande community perception about service excellence in men and women to customer loyalty (study at BTPN Syariah KCP Ciawi). In this study using descriptive quantitative and using anlisis method Likert Scale and Chi Square. Primary data was taken using questionnaire method with sampling using Slovin method as much as Fifty (50) samples from BTPN Syariah KCP Ciawi customer. The result of calculation of Chi Square test shows the difference of perception of society cimande about service excellence in man and woman to customer loyalty, this is indicated by value of chi square result 25,480 which concludes that $\mathrm{H} 0$ is rejected and $\mathrm{H} 1$ accepted means that society cimande agree There are different service excellence in men and women to customer loyalty.
\end{abstract}

Keywords: Public Perception, Service Excellence, Customer Loyalty

\begin{abstract}
ABSTRAK
Penelitian ini memiliki tujuan untuk mengetahui bagaimana persepsi masyarakat cimande mengenai service excellence pada pria dan wanita terhadap loyalitas nasabah (studi di BTPN Syariah KCP Ciawi). Penelitian ini menggunakan deskriptif kuantitatif dan menggunakan analisis metode Skala Likert dan Chi Square. Data primer diambil dengan cara metode kuesioner dengan pengambilan sampel menggunakan metode Slovin sebanyak Lima puluh (50) sampel dari nasabah BTPN Syariah KCP Ciawi. Adapun hasil dari perhitungan uji Chi Square menunjukkan adanya perbedaan persepi masyarakat cimande mengenai service excellence pada pria dan wanita Sterhadap loyalitas nasabah, hal ini ditunjukkan oleh nilai hasil chi square sebesar 25,480 yang menyimpulkan bahwa $\mathrm{H}_{0}$ ditolak dan $\mathrm{H}_{1}$ diterima artinya bahwa masyarakat cimande setuju Ada perbedaan service excellence pada pria dan wanita terhadap loyalitas nasabah.
\end{abstract}


Arfiani Sarah. 2018. Persepsi Masyarakat Mengenai Service Excellence Pria dan Wanita Terhadap Loyalitas Nasabah. Jurnal Nisbah 4 (2): 122-131.

\section{PENDAHULUAN}

Perbankan syariah harus memperhatikan akan loyalitas nasabah terhadap lembaga tersebut agar kegiatan ekonomi tetap berjalan dengan baik sesuai dengan arah perjalanan perkembangan ekonomi, yang menjadi pertimbangan dalam memberikan pelayanan terhadap nasabah agar mempertahankan loyalitasnya pada lembaga yaitu dengan memberikan pelayanan prima (Service Excellence). Dalam menjalankan operasionalnya, salah satu upaya yang dilakukan bank dengan cara meningkatkan service excellence yang dikerjakan oleh pegawai bank pada nasabahnya, agar nasabah bank bisa lebih loyal terhadap bank.

Pemberian Service Excellence yang diberikan pegawai bank terhadap nasabah adalah sebagai alat promosi dalam mempertahankan dan menarik nasabah lebih banyak lagi, terutama dalam perbedaan karakter kepribadian Sumber Daya Insani pria maupun wanita dalam pelayanan yang diberikan pihak bank bisa jadi menjadi salah satu faktor pertimbangan nasabah untuk mempertahankan loyalitasnya di perbankan syariah.

Dalam memberikan pelayanan prima (service excellence) bank harus memperhatikan faktor-faktor yang mendukung kegiatan tersebut, diantaranya adalah reability, emphaty, tangible, assurance, dan responsivences. Faktor-faktor ini akan berjalan dengan memuaskan jika diterapkan secara bersama-sama, sehingga kualitas pelayanan tergantung pada pemilik jasa dalam memenuhi kepuasan nasabah secara konsisten.

Dalam usaha yang dilakukan bank untuk mengetahui tingkat kepuasan nasabah, bank dapat melihat dari perilaku nasabah itu sendiri. Perilaku nasabah adalah kegiatan individu yang terlibat secara langsung dalam menggunakan dan mendapatkan barang dan jasa-jasa. Perilaku konsumen dapat diartikan sebagai kegiatan individu yang terlibat dalam mendapatkan dan menggunakan barang dan jasa secara langsung, termasuk di dalamnya terdapat proses pengambilan keputusan, persiapan, dan penentuan kegiatan-kegiatan. (Swasta, 2000)

Oleh karena itu, salah satu upaya yang dilakukan perusahaan khususnya perusahaan yang bergerak pada bidang jasa perbankan, tepatnya pada BTPN Syariah sebagai salah satu usaha dalam memenuhi kebutuhan dan keinginan nasabah serta ketepatan penyampaian dalam mengimbangi harapan nasabah. Peningkatan kualitas pelayanan yang dilakukan oleh BTPN Syariah selalu berusaha menemukan cara-cara yang mengacu pada kepuasan nasabah, namun masih muncul pertanyaan, apakah hal tersebut benar-benar telah memberikan kepuasan bagi nasabah dilihat dari aspek lima dimensi pelayanan reability (Kehandalan), emphaty (Empati), tangible (Bukti Langsung), assurance (Jaminan), dan responsiveness (Daya Tanggap) dan perbedaan karakteristik kepribadian Sumber Daya Insani (SDI) atau karyawan, sehingga BTPN Syariah perlu menilai apakah pelayanan yang diberikan sudah sesuai dengan harapan nasabah. Hal ini menjadi bukti perhatian pihak BTPN Syariah dalam memenuhi kepuasan nasabahnya.

BTPN Syariah harus dapat memilih bentuk kebijakan maupun teknologi yang paling tepat digunakan dalam mencapai tujuan, hal tersebut dapat mempengaruhi pelayanan terhadap kepuasan nasabah, sehingga dapat disimpulkan bahwa faktor yang dapat mendorong pangsa pasar suatu perusahan terutama di bidang jasa 
perbankan saalah satunya adalah dengan adanya kualitas pelayanan. Minat masyarakat akan tumbuh semakin besar jika bank tersebut memiliki kualitas pelayanan yang baik. Perlu dilakukan sosialisasi perbankan syariah utnuk meningkatkan minat masyarakat dalam bertransaksi di lembaga keuangan syariah dengan memberikan kualitas pelayanan yang baik.

Berdasarkan latar belakang yang telah diuraikan, penulis terdorong untuk menyusun dan melakukan penelitian denga judul: "Persepsi Masyarakat Mengenai Service Excellence Pria dan Wanita Terhadap Loyalitas Nasabah"

\section{MATERI DAN METODE}

\section{Tinjauan Pustaka}

Persepsi bisa diartikan sebagai proses dengan mana individu-individu dapat mengelola dan menafsirkan kesan panca indera mereka sehingga memberi arti untuk lingkungan mereka (Robbins, 2001:88). Sejalan dari definisi tersebut persepsi pada dasarnya adalah proses psikologis yang dialami oleh seluruh individu dalam memahami informasi tentang lingkungannya baik melalui penglihatan maupun pendengaran (Thoha, 1998:23). Persepsi seseorang pada suatu sasaran bisa bertentangan dengan persepsi orang lain, hal ini dipengaruhi oleh beberapa faktor.

Pengertian pelayanan prima adalah kegiatan untuk memberikan pelayanan yang baik dalam memenuhiharapann dan kebutuhan pelanggan, dalam kata lain pelayanan prima adalah kegiatan memberikan pelayanan hingga terpenuhinya standar kualitas.

Setiap perusahaan membutuhkan pelayanan prima dalam memenuhi kebutuhan pelanggan (nasabah). Adapun bentuk pelayanan prima yang sesuai dengan SOP adalah pelayanan yang dikerjakan dengan ramah-tamah, cepat, tepat, dan nyaman sehingga memenuhi kepuasan nasabahnya. (Hasibuan,
2001:150). Pelayanan yang berkualitas dapat tercermin pada perusahaan yang menerapkan kinerjanya pada aspek-aspek seperti reability, emphaty, tangible, assurance, dan responsiveness. Kelima aspek ini akan memberikan kualitas yang baik dan memuaskan jika diterapkan secara bersama-sama, sehingga kualitas pelayanan tergantung pada pemilik jasa dalam memenuhi kepuasan nasabah secara konsisten. (Tjiptono, 2000).

\section{Jenis Penelitian}

Penelitian ini menggunakan jenis penelitian deskriptif dengan pendekatan kuantitatif. Penelitian kuantitatif adalah metode penelitian yang didasarkan pada filsafat positivisme, yang digunakan untuk meneliti populasi atau sampel tertentu, pengumpulan data menggunakan alat penelitian, analisis data bersifat kuantitatif/statistik, dengan tujuan untuk menguji hipotesis yang telah ditetapkan (Sugiyono, 2014:8). Keleluasan informasi biasanya lebih ditekankan dalam penelitian kuantitatif, sehingga metode ini cocok digunakan untuk populasi yang luas dengan variabel yang terbatas (Sugiyono, 2014:12).

Jenis penelitian deskriptif dengan pendekatan kuantitatif bertujuan untuk memberikan penjelasan secara terperinci tentang perbandingan service excellence pada pria dan wanita terhadap loyalitas nasabah. Sehingga strandar yang sudah ditetapkan dapat seuai yang diharapkan.

\section{Populasi dan Sampel}

Populasi adalah wilayah generalisasi yang terdiri dari obyek/subyek yang mempunyai kualitas dan karakteristik tertentu yang ditetapkan oleh peneliti untuk dipelajari dan kemudian ditarik kesimpulannya (Sugiyono, 2014:80). Sampel adalah bagian dari jumlah dan karakteristik yang dimiliki oleh populasi tersebut (Sugiyono, 2014:81).

Sampel dari penelitian ini adalah Nasabah BTPN Syariah Di Desa Cimande. Penetapan jumlah sampel sesuai dengan pendapat yang menyatakan : "Biasanya besarnya sampel tergantung pada 
besarnya populasi yang akan diteliti. Sekalipun sulit untuk mendapatkan aturan tentang besarnya sampel, 30 responden adalah jumlah minimum yang disebutkan oleh ahli-ahli metodologi penelitian" (Malo,1997:171).

Populasi dalam penelitian ini ditekankan pada nasabah BTPN Syariah KCP Ciawi Di Desa Cimande, Sedangkan teknik penarikan sampel yang akan digunakan dalam penelitian ini yaitu berdasarkan random sampling.

\section{Teknik Sampling}

Teknik sampling yang digunakan dalam penelitian ini menggunakan metode random sampling, teknik sampling adalah cara yang digunakan untuk menentukan sampel yang jumlahnya sesuai dengan ukuran sampel yang akan dijadikan sumber data sebenarnya, dengan memperhatikan sifat-sifat dan penyebaran populasi agar diperoleh sampel yang representatif(Margono, 2004: 125).

\section{Jenis dan Sumber Data}

Jenis data yang dipakai dalam penelitian ini terdiri atas data primer dan sekunder. Data-data tersebut diperoleh melalui:

1. Data Primer, yaitu data pokok yang menjadi sumber dalam penelitian, dilakukan melalui wawancara, dan alatalat lainnya (Arikumto, 2010:145). Data primer dalam penelitian ini diperoleh dari hasil wawancara, dan kuesioner yang disebar kepada nasabah BTPN Syariah Di Desa Cimande

2. Data Sekunder, yaitu data yang digunakan untuk data pendukung dan penunjang dalam penelitian (Arikumto, 2010:157). Data sekunder didapat dari data-data internal BTPN Syariah, bukubuku, jurnal, dan bahan pustaka lainnya yang memiliki keterkaitan dengan penelitian ini.

\section{Teknik Pengumpulan Data}

Adapun tata cara pengumpulan data yang digunakan dalam penelitian ini adalah:

1. Kuesioner adalah cara pengumpulan data yang dilakukan dengan memberikan pertanyaan pertanyaan atau pernyataan tertulis pada responden untuk dijawabnya (Sugiyono, 2014:142). Dalam penelitian ini, kuesioner digunakan untuk mengetahui perbandingan service excellence pada pria dan wanita terhadap loyalitas nasabah Kuisioner menggunakan skala likert, skala ini berhubungan dengan pertanyaan mengenai pendapat seseorang terhadap sesuatu, misalnya setuju dan tidak setuju, senang dan tidak senang, baik dan tidak baik (Umar, 2005: 89).Dengan rumusan sebagai berikut:

Tabel 1. Skala Likert

\begin{tabular}{|c|c|}
\hline Bobot & Kategori \\
\hline 5 & Sangat Setuju \\
\hline 4 & Setuju \\
\hline 3 & Kurang Setuju \\
\hline 2 & Tidak Setuju \\
\hline 1 & Sangat Tidak Setuju \\
\hline
\end{tabular}

Sumber: Umar, 2005: 89

Dengan menggunakan skala likert 5 poin. Skala ini digunakan dengan cara memberikan daftar pertanyaan pada responden, dengan menjawab berdasar tingkatan jawaban yang tersedia. Mulai dari sangat setuju, setuju, kurang setuju, tidak setuju, sangat tidak setuju.

2. Wawancara

Menurut Esterberg dan Sugiyono (2014:231) mendefinisikan bahwa wawancara (interview) adalah pertemuan dua orang untuk memberikan informasi dan ide melalui tanya jawab, sehingga bisa disimpulkan makna dalam suatu topik tertentu. Wawancara yang digunakan peneliti adalah wawancara semi terstruktur, dimana peneliti berusaha menggali informasi yang lebih mendalam tentang objek yang diteliti, sehingga peneliti mendapatkan gambaran permasalahan lebih lengkap dan akurat.Wawancara ini dilakukan kepada nasabah BTPN Syariah Di Desa Cimande.

3. Mengakses website/situs internet

Metode ini dilakukan dengan menelusuri website/situs yang 
menyediakan informasi yang berkaitan dengan penelitian ini.

\section{Teknik analisis Data}

1. Uji Validasi Menurut Sugiyono (2013:267),Uji validasi merupakan validitas tingkat kebenaran antara data yang terjadi pada obyek penelitian dengan daya yang dapat dipaparkan oleh peneliti. Dengan begitu data yang valid adalah data "yang tidak berbeda" antara data yang dilaporkan oleh peneliti dengan data yang terjadi dilapangan pada obyek penelitian

2. Uji reliabilitas menunjukkan pada pengertian bahwa alat yang digunakan dapat mengukur sesuatu yang diukur secara konsisten dari waktu ke waktu. Syarat kualifikasi suatu alat pengukur adalah konsisten atau tidak berubahubah. Instrumen yang diuji reliabilitasnya adalah instrumen yang dibuat oleh peneliti. Dalam hal ini instrumen tersebut adalah instrumen komponen konteks, masukan, proses dan hasil. Reliabilitas ditentukan atas dasar proporsi varian total yang merupakan varian total sebenarnya. Makin besar proporsi tersebut berarti makin tinggi reliabilitasnya. (Saifuddin, 2012:110)

Penjelasan :

a. Jika alpha $>0,90$ maka reliabilitas sempurna

b. Jika alpha antara 0,70 - 0,90 maka reliabilitas tinggi

c. Jika alpha antara 0,50 - 0,70 maka reliabilitas moderat

d. Jika alpha $<0,50$ maka reliabilitas rendah

3. Skala likert digunakan untuk mengukur sikap, pendapat dan persepsi seseorang atau sekelompok orang tentang fenomena sosial (Sugiyono, 2015:136). Dengan skala likert, maka variabel yang akan diukur dijabarkan menjadi indikator variabel. Kemudian indikator tersebut dijadikan sebagai titik tolak untuk menyusun item-item instrumen yang dapat berupa pernyataan atau pertanyaan
4. Test Chi-Kuadrat (Chi-Square) adalah salah satu penggunaan statistik adalah untuk memutuskan apakah sebuah hipotesis di tolak atau tidak, teknik ini dilakukan apabila jumlah pupulasi lebih dari 30. Teknik ini sesuai digunakan pada penelitian ini untuk mengetahui keadaan hipotesisnya.

Hipotesis dapat diuji dengan mengguanakan rumus :

Dimana:

$$
x^{2}=\frac{\left(f_{o}-f_{h}\right)^{2}}{f_{n}}
$$

$\mathrm{X}^{2}=$ chi kuadrat

Fo = frekuensi yang

diobservasikan

Fh = Frekuensi yang

diharapkan

\section{HASIL DAN PEMBAHASAN}

\section{Gambaran Umum}

BTPN Syariah merupakan Bank Umum Syariah (BUS) ke 12 di Indonesia, BTPN syariah adalah salah satu bank di Indonesia yang memiliki tujuan untuk agar rakyat Indonesia mempunyai kehidupan yang lebih baik. BTPN Syariah terbentuk dari dua perpaduan bank yaitu PT. Bank Sahabat Purbadanarta dan Unit Usaha Syariah BTPN (UUS BTPN).Bank Sahabat Purbadanarta berdiri dari bulan Maret 1991 di Semarang, adalah bank umum non devisa yang $70 \%$ sahamnya dimiliki oleh PT Bank Tabungan Pensiunan Nasional, Tbk (BTPN) 20 Januari 2014 dirubah menjadi BTPN Syariah berdasarkan Surat Keputusan Otoritas Jasa Keuangan (OJK) tanggal 22 Mei 2014. Unit Usaha Syariah BTPN yang ditekankan untuk melayani dan memberdayakan keluarga prasejahtera di seluruh Indonesia adalah salah satu segmen bisnis di PT Bank Tabungan Pensiunan Nasional Tbk sejak Maret 2008, kemudian di spin off dan ikut serta dengan BTPN Syariah pada Juli 2014.

Melalui produk dan aktivitasaktivitas yang dilakukan oleh BTPN syariah yang bertekad untuk memajukan 
rakyat Indonesia agar mempunyai kehidupan yang lebih maju, BTPN Syariah menganjurkan dan melibatkan semua stakeholders bekerja sama untuk memberikan kemudahan pada masyarakat untuk menggunakan atau memanfaatkan produk dan jasa-jasa bank.

\section{Analisis Statistik Deskriptif}

Jumlah responden atau nasabah yang diteliti adalah sebanyak 50 orang, penilitian ini dilihat dari karakteristik nasabah dari jenis kelamin, usia, pekerjaan, penghasilan perbulan dan lama menjadi nasabah bank.

a. Jenis kelamin responden

Tabel 2. Jenis kelamin responden

\begin{tabular}{|c|l|c|c|}
\hline No & $\begin{array}{c}\text { Jenis } \\
\text { kelamin }\end{array}$ & $\begin{array}{c}\text { Jumlah } \\
\text { responden }\end{array}$ & $\begin{array}{c}\text { Persentas } \\
\text { e }\end{array}$ \\
\hline 1 & Laki-laki & 10 & $20 \%$ \\
\hline 2 & $\begin{array}{l}\text { Peremp } \\
\text { uan }\end{array}$ & 40 & $80 \%$ \\
\hline & Jumlah & 50 & $100 \%$ \\
\hline
\end{tabular}

b. Tingkat usia responden

Tabel 3. Usia responden

\begin{tabular}{|c|c|c|c|}
\hline $\begin{array}{l}\mathbf{N} \\
\mathbf{O}\end{array}$ & $\begin{array}{c}\text { Tingkat } \\
\text { Usia } \\
\text { Responde } \\
\text { n }\end{array}$ & $\begin{array}{l}\text { Jumlah } \\
\text { Respond } \\
\text { en }\end{array}$ & $\begin{array}{c}\text { Persentas } \\
\text { e }\end{array}$ \\
\hline 1 & $<20$ tahun & 4 & $8 \%$ \\
\hline 2 & $\begin{array}{l}20-30 \\
\text { Tahun }\end{array}$ & 28 & $56 \%$ \\
\hline 3 & $\begin{array}{l}31-40 \\
\text { Tahun }\end{array}$ & 13 & $26 \%$ \\
\hline 4 & $\begin{array}{l}41-50 \\
\text { Tahun }\end{array}$ & 4 & $8 \%$ \\
\hline 5 & $>50$ Tahun & 1 & $2 \%$ \\
\hline \multicolumn{2}{|c|}{ Jumlah } & 50 & $100 \%$ \\
\hline
\end{tabular}

c. Pekerjaan Responden

Tabel 4. Pekerjaan responden

\begin{tabular}{|c|l|c|c|}
\hline NO & $\begin{array}{l}\text { Pekerjaan } \\
\text { Responden }\end{array}$ & Jumlah & Persentase \\
\hline 1 & $\begin{array}{l}\text { Pelajar/ } \\
\text { Mahasiswa }\end{array}$ & 10 & $20 \%$ \\
\hline 2 & $\begin{array}{l}\text { Pegawai } \\
\text { Swasta }\end{array}$ & 5 & $10 \%$ \\
\hline 3 & Guru & 1 & $2 \%$ \\
\hline 4 & Wiraswasta & 4 & $8 \%$ \\
\hline
\end{tabular}

\begin{tabular}{|c|l|c|c|}
5 & PNS & 5 & $10 \%$ \\
\hline 6 & Lainnya & 25 & $50 \%$ \\
\hline \multicolumn{2}{|c|}{ JUMLAH } & 50 & $100 \%$ \\
\hline
\end{tabular}

d. Lama Menjadi Nasabah

Tabel 5. Lama Menjadi Nasabah

\begin{tabular}{|r|c|r|r|}
\hline No & $\begin{array}{c}\text { Lama Menjadi } \\
\text { Nasabah }\end{array}$ & Jumlah & Persentase \\
\hline 1 & $1-3$ tahun & 33 & $66 \%$ \\
\hline 2 & $3-5$ tahun & 11 & $22 \%$ \\
\hline 3 & $>5$ tahun & 6 & $12 \%$ \\
\hline \multicolumn{2}{|c|}{ Jumlah } & \multicolumn{2}{|c|}{50} \\
\hline
\end{tabular}

\section{Uji Relibilitas dan Validitas}

Realibilitas adalah istilah yang dipakai untuk menunjukkan sejauh mana suatu hasil pengukuran relatif konsisten apabila alat ukur itu digunakan berulang kali, langkah lain jangan dijadikan alat untuk mengukur panjang karena tiap-tiap langkah tidak sama panjangnya (Abdullah, 2015:256). Uji reliabilitas dari masingmasing faktor cronbach's alpha. Dibawah ini hasil uji reliabilitas adalah sebagai berikut:

\section{Tabel 6. Uji Hasil Reliabilitas}

\begin{tabular}{|r|r|r|}
\hline $\begin{array}{c}\text { Cronbach } \\
\text { 's Alpha }\end{array}$ & $\begin{array}{c}\text { Cronbach's } \\
\text { Alpha Based } \\
\text { on } \\
\text { Standardized } \\
\text { Items }\end{array}$ & N of Items \\
\hline, 928 &, 932 & 29 \\
\hline
\end{tabular}

Pada tabel uji reliabilitas di atas, kuisioner dinyatakan jika mempunyai nilai koefisien alpha yang lebih besar daripada 0,6 . Maka dari hasil tersebut pengujiannya dinyatakan reliable karena nilai koefisien croanbach's alpha diperoleh lebih besar dari nilai 0,6 yaitu $0,928 \quad(0,928>0,6)$. Sehingga hasil uji penelitian ini cukup handal dalam mengukur persepsi masyarakat terhadap variabel yang akan diteliti dan dapat dilanjukten penelitian tersebut ke tahap selanjutnya.

Validitas adalah untuk meyatakan sejauhmana data yang didapatkan melalui instrumen penelitian (kuesioner) akan mengukur apa yang ingin diukur 
(Abdullah, 2015:256). Uji validitas menunjukan sejauhmana suatu alat pengukur untuk mengukur apa yang akan diukur (Abdullah, 2015:258).Dalam hasil pengolahan data, bahwa koefisien korelasi dari 37 pertanyaan yang ada, dapat disimpulkan 31 yang valid dengan skor > 0,278 dan dapat diolah secara lanjut.

\section{Hasil Uji Chi Square}

a. Informasi nasabah BTPN Syariah Desa Cimande mengenai Reability karyawan BTPN syariah

Berdasarkan perhitungan Chi Kuadrat, maka nilai chi kuadrat hitung = 27,160a untuk karyawan pria dan 22, 840a untuk karyawan wanita dengan derajat kebebasan $(\mathrm{dk})=\mathrm{n}-1=5-1=4$. Berdasarkan $\mathrm{dk}=4$ dengan taraf signifikan sebesar 1\%, maka diperoleh nilai Chi Kuadrat tabel $=13,277$ (terlampir). Diketahui bahwa nilai Chi Kuadrat hitung lebih besar dari nilai Chi Kuadrat tabel $(27,160>13,277)$ dan $(22,840>13,277)$. Dengan demikian Ho ditolak dan $\mathrm{Ha}$ diterima atau dapat dikatakan bahwa masyarak cimande setuju Ada perbedaan service excellencepada pria dan wanita terhadap loyalitas nasabah.

b. Informasi Nasabah BTPN Syariah Desa Cimande mengenai Emphaty karyawan BTPN syariah

Berdasarkan hasil perhitungan Chi Kuadrat, maka nilai Chi Kuadrat hitung = $27,160^{\text {a }}$ untuk karyawan pria dan 21,200 a untuk karyawan wanita dengan derajat kebebasan $(\mathrm{dk})=\mathrm{n}-1=5-1=4$. Berdasarkan $\mathrm{dk}=4$ dengan taraf signifikan sebesar 1\%, maka diperoleh nilai Chi Kuadrat tabel $=13,277$ (terlampir). Diketahui bahwa nilai Chi Kuadrat hitung lebih besar dari nilai Chi Kuadrat tabel $\left(27,160^{a}>13,277\right)$ dan $(21,200 a>13,277)$.Dengan demikian Ho ditolak dan $\mathrm{Ha}$ diterima atau dapat dikatakan bahwa masyarak cimande setuju Ada perbedaan service excellence pada pria dan wanita terhadap loyalitas nasabah. c. Informasi nasabah BTPN Syariah Desa Cimande mengenai Tangible karyawan BTPN syariah

Berdasarkan hasil perhitungan Chi Kuadrat, maka nilai Chi Kuadrat hitung = 12,880 a untuk karyawan pria dan 21,200a untuk karyawan wanita dengan derajat kebebasan $(\mathrm{dk})=\mathrm{n}-1=5-1=4$. Berdasarkan $\mathrm{dk}=4$ dengan taraf signifikan sebesar 1\%, maka diperoleh nilai Chi Kuadrat tabel $=13,277$ (terlampir). Diketahui bahwa nilai Chi Kuadrat hitung lebih besar dari nilai Chi Kuadrat tabel $(12,880 a<13,277)$ dan $(21,200 a>13,277)$.Dengan demikian Ho ditolak dan $\mathrm{Ha}$ diterima atau dapat dikatakan bahwa masyarak cimande setuju Ada perbedaan service excellence pada pria dan wanita terhadap loyalitas nasabah.

d. Informasi Nasabah BTPN Syariah Desa Cimande mengenai Assurance Karyawan BTPN Syariah

Berdasarkan hasil perhitungan Chi Kuadrat, maka nilai Chi Kuadrat hitung = 11,760untuk karyawan pria dan 10, 320 untuk karyawan wanita dengan derajat kebebasan $(\mathrm{dk})=\mathrm{n}-1=5-1=4$. Berdasarkan $\mathrm{dk}=4$ dengan taraf signifikan sebesar 1\%, maka diperoleh nilai Chi Kuadrat tabel $=13,277$ (terlampir). Diketahui bahwa nilai Chi Kuadrat hitung lebih besar dari nilai Chi Kuadrat tabel $(11,760<13,277)$ dan $(10,320<13,277)$.Dengan demikian Ho diteria dan $\mathrm{Ha}$ ditolak atau dapat dikatakan bahwa masyarak cimande setuju tidak Ada perbedaan service excellence pada pria dan wanita terhadap loyalitas nasabah.

e. Informasi nasabah BTPN Syariah Desa Cimande mengenai Responsivences karyawan BTPN syariah

Berdasarkan hasil perhitungan Chi Kuadrat, maka nilai Chi Kuadrat hitung = 27,160 untuk karyawan pria dan $14,560^{\text {a }}$ untuk karyawan wanita dengan derajat kebebasan $(\mathrm{dk})=\mathrm{n}-1=5-1=4$. Berdasarkan $\mathrm{dk}=4$ dengan taraf signifikan sebesar 1\%, maka diperoleh 
nilai Chi Kuadrat tabel $=13,277$ (terlampir). Diketahui bahwa nilai Chi Kuadrat hitung lebih besar dari nilai Chi Kuadrat tabel $(27,160>13,277)$ dan $(20,320>13,277)$.Dengan demikian Ho ditolak dan $\mathrm{Ha}$ diterima atau dapat dikatakan bahwa masyarak cimande setuju Ada perbedaan service excellence pada pria dan wanita terhadap loyalitas nasabah.

f. Informasi nasabah BTPN Syariah Desa Cimande mengenai Loyalitas nasabah

Berdasarkan hasil perhitungan Chi Kuadrat, maka nilai Chi Kuadrat hitung = 27,160 dengan derajat kebebasan $(\mathrm{dk})=\mathrm{n}$ $-1=5-1=4$. Berdasarkan $\mathrm{dk}=4$ dengan taraf signifikan sebesar 1\%, maka diperoleh nilai Chi Kuadrat tabel $=13,277$ (terlampir). Diketahui bahwa nilai Chi Kuadrat hitung lebih besar dari nilai Chi Kuadrat tabel $(27,160>13,277)$.Dengan demikian Ho ditolak dan Ha diterima atau dapat dikatakan bahwa masyarak cimande setuju Ada perbedaan service excellence pada pria dan wanita terhadap loyalitas nasabah.

\section{KESIMPULAN DAN IMPLIKASI}

\begin{tabular}{lll}
\multicolumn{1}{c}{ Dalam penelitian ini } & jumlah \\
responden & wanita dengan jumlah \\
responden pria berbeda, dimana & den \\
responden wanita lebih banyak & dibandingkan dengan responden pria oleh \\
dibarena itu mempengaruhi jawaban. Maka \\
penulis dapat mengambil kesimpulan \\
sebagai berikut:
\end{tabular}

1. Berdasarkan hasil dari perhitungan Chi Kuadrat beberapa faktor menunjukkan bahwa nilai Chi Kuadrat hitung lebih besar dibandingkan nilai Chi Kuadrat tabel yang berarti Ho ditolak dan $\mathrm{Ha}$ diterima, artinya masyarakat cimande setuju ada perbedaan service excellence pada pria dan wanita terhadap loyalitas nasabah.

2. Berdasarkan hasil perhitungan Chi Kuadrat faktor yang menunjukan bahwa nilai chi kuadrat hitung lebih kecil dibandingkan nilai chi kuadrat tabel yang berarti Ho diterima dan $\mathrm{Ha}$ ditolak, artinya masyarakat cimande tidak setuju ada perbedaan service excellence pada pria dan wanita terhadap loyalitas nasabah. beberapa faktor yang dimaksud adalah: Reability (Karyawan selalu memberikan pelayanan terhadap nasabah secara tuntas) dengan nilai chi kuadrat hitung 5,320 untuk karyawan pria dan ,280 untuk karyawan wanita. Emphaty front liner Front liner dalam melakukan pelayanan terhadap nasabah selalu menyebutkan nama terlebih dahulu) dengan nilai chi kuadrat hitung ,280 untuk karyawan pria dan ,160 untuk karyawan wanita. Tangible (Meja kerja selalu berada dalam keadaan rapi dan tertata serta dilengkapi oleh ATK, formulir aplikasi dan papan nama) dengan nilai chi kuadrat hitung ,280 untuk karyawan pria dan ,160 untuk karyawan wanita. Assurance (Karyawan selalu bersikap sopan dalam melayani nasabah) dengan perhitungan chi kuadrat hitung sebesar 4,480 a untuk karyawan pria dan 6,880auntuk karyawan wanita. (Mampu menyelesaikan masalah dengan waktu yang telah dijanjikan kepada nasabah.) dengan nilai chi kuadrat hitung 4,480a untuk karyawan pria dan 5,320auntuk karyawan wanita. Responsiveness (Karyawan tidak melakukan kesalahan dalam melakukan pelayanan) dengan hasil perhitungan chi kuadrat hitung mempunyai nilai sebesar, $280^{\mathrm{a}}$ untuk karyawan pria dan 2,440 a untuk karyawan wanita.

\section{DAFTAR PUSTAKA}

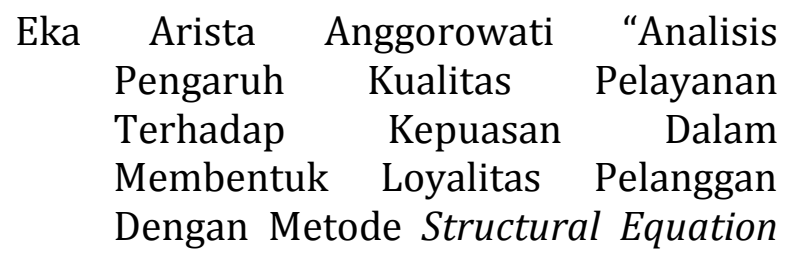


Modelling Serta Usulan Peningkatan Pelayanan Kereta Api (Studi Kasus Kereta Api Majapahit Relasi MalangPasar Senen)

Erlando. Analisis Pengaruh Pelayanan Prima (Service Excellence) Terhadap Kepuasan Pelanggan (Studi Pada SPBU Pertamina 34-12708)

Idris, muhammad. 2016. Analisis mutu layanan elektronik delevery channel

terhadap kepuasan nasabah (study pada BNI syariah)

Jadydatul Adawiyah, Aulia. Implementasi Service Excellence Oleh Customer Service Pada BMT Bismillah Sukorejo

Lynda Silviani Wati "Penerapan Service Excellence Terhadap Pelayanan di Galeri Indosat Cabang Solo

M. Zainul whatani. 2012. Konsep service excellence perbankan syariah berdasarkan Al-Qur'an

Novita. 2016. Pengaruh Pelayanan Prima Terhadap Kepuasan Nasabah Pada PT. Bank Mandiri (Persero) Tbk Cabang Kartini Makassar

Nugrahaningsih, Putri. Analisis Perbedaan Perilaku Etis Auditor Di Kapdalam Etika Profesi (Studi Terhadap Peran Faktor Faktor Individual : Locu Of Kontrol, Lama Pengalaman Kerja, Gender Dan Equity Sensitivity)

Permana, Yuda.2015. Pengaruh aktivitas media tweitter BRI Syariah terhadap kepuasan nasabah BRI Syariah

Sanjaya, Rangga. Multimedia Interaktif Pelatihan Service Excellence Menggunakan Pendekatan Story Based Learning

Vianny Marselita, Priska \& Veranita Goenawan. Analisis Perbandingan Harapan Dan Persepsi Pria Dan Wanita Dalam Memilih Sebuah Rstoran Disurabaya Ditinjau Dari Segi Meal Experince

Afika Niandani, Deny. Analisis Pengaruh Pelayanan Prima (Service Excellence) Terhadap Kepuasan Konsumen (Studi Pada SPBU Pertamina

$\begin{array}{lll}44.557 .07 & \text { Sendang } & \text { Mulyo } \\ \text { Karanganyar) } & & \end{array}$

Awaliyah, Dewi Sufi. 2016. Persepsi Masyarakat Bogor Mengenai Kemitraan Bank Syariah. Skripsi. Universitas Djuanda Bogor. Bogor

Ashari, Rizka. Penerapan Pelayanan Prima Oleh Forntliner Dalam Upaya Menjaga Kepuasan Nasabah Pada Bank Muamalat Indonesia Cabang Purwokerto

Desi Mayasari, Peran Pelayanan Prima (Service Excellence) Terhadap Kepercayaan Nasabah Di PT Bank Syariah Mandiri Cabang Malang

Hani, Atus Sholikhah. Bahasa Pria Dan Wanita :Kajian Sosiolinguistis Pada Mahasiswa Universitas PGRI Palembang

Kartikasari, Ayu, 2009. Peran Customer Service Dalam Meningkatkan Pelayanan Terhadap Nasabah Di Bank Tabungan Pensiunan Nasional (BTPN)

Novita, Meilastri. Pengaruh Pelayanan Prima Terhadap Kepuasan Nasabah Pada PT. Bank Mandiri (Persero) Tbk Cabang Kartini Makassar

Sallehudin. 2006. Analisa Pengaruh Pelayanan Prima Terhadap Kepuasan Pelanggan (Studi Pada Kantor Cabang Perum Pegadaian Yang Berada Dikota Malang)

Silvester Kukuh, Pengaruh Variable Pelayanan Prima Terhadap Kepuasan Nasabah (Studi Kasus Pada Bank Negara Indonesa Cabang Jalan Margonda Raya)

Ulil Khakim, Fuad. Pengaruh Pelayanan Prima (Service Excellence) Terhadap Kepuasan Nasabah (Studi Kasus BPD DIY Syaria'ah Cabang Cik Ditiro)

Barata, Atep Adya. 2004. Dasar-Dasar Pelayanan Prima. Jakarta: Elex Media Komputindo

Wahyu Widhiarso "Uji Hipotesis Komparatif" Http://Widhiarso.Staff.Ugm.Ac.Id 
Suharsimi Arikunto, Prosedur Penelitian Suatu Pendekatan Praktek (Jakarta: PT Rineka Cipta, 2006) Hal 134 http://www.kajianpustaka.com/2013/01/ pengertian-dan-fungsiperbankan.html 